\title{
Selection of metal ion irradiation for controlling Ti1-xAlxN alloy growth via hybrid HIPIMS/magnetron co-sputtering
}

\author{
Grzegorz Greczynski, Jun Lu, M Johansson, Jens Jensen, Ivan Petrov, \\ Joseph E Greene and Lars Hultman
}

\section{Linköping University Post Print}

\begin{abstract}
N.B.: When citing this work, cite the original article.
\end{abstract}
Original Publication:

Grzegorz Greczynski, Jun Lu, M Johansson, Jens Jensen, Ivan Petrov, Joseph E Greene and Lars Hultman, Selection of metal ion irradiation for controlling Ti1-xAlxN alloy growth via hybrid HIPIMS/magnetron co-sputtering, 2012, Vacuum, (86), 8, 1036-1040.

http://dx.doi.org/10.1016/j.vacuum.2011.10.027

Copyright: Elsevier

http://www.elsevier.com/

Postprint available at: Linköping University Electronic Press

http://urn.kb.se/resolve?urn=urn:nbn:se:liu:diva-77108 


\title{
Selection of metal ion irradiation for controlling $\operatorname{Ti}_{1-x} \mathrm{Al}_{x} \mathrm{~N}$ alloy growth via hybrid HIPIMS/magnetron co-sputtering
}

\author{
G. Greczynski, ${ }^{1}$ J. Lu, ${ }^{1}$ M. Johansson, ${ }^{2}$ J. Jensen, ${ }^{1}$ I. Petrov, ${ }^{1,3}$ J.E. Greene, ${ }^{1,3,4}$ and L. Hultman ${ }^{1}$ \\ ${ }^{1}$ Department of Physics (IFM), Linköping University, SE-581 83 Linköping, Sweden \\ ${ }^{2}$ Seco Tools AB, Björnbacksvägen 2, SE-737 82 Fagersta, Sweden \\ ${ }^{3}$ Frederick Seitz Materials Research Laboratory, University of Illinois, Urbana, Illinois 61801 \\ and Materials Science Department, University of Illinois, Urbana, Illinois 61801 \\ ${ }^{4}$ Department of Physics, University of Illinois, Urbana, Illinois 61801, USA
}

\begin{abstract}
We demonstrate, for the first time, the growth of metastable single-phase $\mathrm{NaCl}$-structure high-AlN-content $\operatorname{Ti}_{1-x} \mathrm{Al}_{x} \mathrm{~N}$ alloys $(\mathrm{x} \leq 0.64)$ which simultaneously possess high hardness and low residual stress. The films are grown using a hybrid approach combining high-power pulsed magnetron (HPPMS/HIPIMS) and dc magnetron sputtering of opposing metal targets. With HIPIMS applied to the $\mathrm{Al}$ target, $\mathrm{Al}^{\mathrm{n}+}$ ion irradiation (dominated by $\mathrm{Al}^{+}$) of the growing film results in alloys $0.55 \leq \mathrm{x} \leq 0.60$ which exhibit hardness $H \sim 30 \mathrm{GPa}$ and low stress $\sigma=0.2-0.7$ GPa, tensile. In sharp contrast, films with corresponding AlN concentrations grown with HIPIMS applied to the Ti target, giving rise to $\mathrm{Ti}^{\mathrm{n}+}$ ion irradiation (with a significant $\mathrm{Ti}^{2+}$ component), are two-phase -- cubic (Ti,Al)N and hexagonal AlN -- with low hardness, $H=18-19 \mathrm{GPa}$, and high compressive stress ranging up to $2.7 \mathrm{GPa}$. Annealing alloys grown with HIPIMS applied to the $\mathrm{Al}$ target results in age hardening due to spinodal decomposition; the hardness of $\operatorname{Ti}_{0.41} \mathrm{Al}_{0.59} \mathrm{~N}$ increases from 30 to $33 \mathrm{GPa}$ following a $900{ }^{\circ} \mathrm{C}$ anneal.
\end{abstract}

Keywords: HIPIMS; HPPMS; TiAlN; ionized PVD 
It has been shown previously that both the ion kinetic energy $E_{i}$ and the ion-to-metal flux ratio $J_{i} / J_{M e}$ incident at the growth front during $\mathrm{T}_{0.5} \mathrm{Al}_{0.5} \mathrm{~N}$ deposition significantly affect the microstructure and physical properties of alloys grown by dc magnetron sputtering (DCMS). ${ }^{1}$ Low values of $E_{i}(\leq 20 \mathrm{eV})$ combined with high $J_{i} / J_{M e}$ values $(\geq 5.2)$ lead to densification, larger grain size, and low residual stresses. Conversely, high values of $E_{i}(\geq 100 \mathrm{eV})$ result in excess $\mathrm{N}$ incorporation, residual point defect concentrations, decreased average column widths, high compressive stresses, and formation of second-phase hexagonal-structure AlN precipitates. ${ }^{2}$ A potentially attractive and unique feature of high-power pulsed magnetron sputtering (HPPMS/HIPIMS) $^{3}$ is the ability to ionize up to $90 \%$ of the sputtered metal flux ${ }^{4}$ depending upon the metal, while high real-time sputtering rates minimize, due to rarefaction, ${ }^{5-6}$ the concentration of rare-gas atoms trapped in the film. Gas incorporation, and associated recoil implantation processes, result in intrinsic compressive stress. ${ }^{7}$ An additional advantage of HIPIMS is enhanced momentum transfer provided by accelerated ionized sputtered metal atoms during bias deposition, which allows the use of lower $E_{i}$ values, thereby reducing the concentration of residual defects, while still enhancing adatom mobilities.

A potential disadvantage of HIPIMS is the production of multiply-charged metal ions $(n \geq$ 2) during intense plasma pulses. ${ }^{8,9}$ Upon application of a substrate bias $V_{s}$, the energy gain is $n \times \mathrm{e} V_{s}$ per ion which can result in residual lattice damage even for moderate to low $V_{s}$ values.

In this letter, we report results for the growth and mechanical properties of metastable $\mathrm{NaCl}$-structure $\mathrm{Ti}_{1-x} \mathrm{Al}_{x} \mathrm{~N}$ alloys, known to be sensitive to ion damage giving rise to second-phase formation, ${ }^{2}$ as a model system to probe the effects of the metal-ion charge state during film growth. We show that low-energy irradiation promotes near-surface mixing with no detectable residual defects. We use co-sputtering from separate elemental metal targets, $\mathrm{Al}$ and $\mathrm{Ti}$, in a 
hybrid HIPIMS/DCMS configuration in which the targets are switched in independent sets of experiments. This allows us to separately probe the role of intense $\mathrm{Ti}^{n+}$ and $\mathrm{Al}^{+}$ion fluxes $(n=$ 1,2) from HIPIMS-powered targets on film growth kinetics, microstructure, and physical properties. In these experiments, we investigate the composition range $0.53 \leq x \leq 0.76$ in order to determine the effect of metal ion flux on the maximum metastable cubic AlN solubility $x_{\max }$ across the range of previously reported results, from $x_{\max } \sim 0.50$ for DCMS ${ }^{10,11}$ to $\sim 0.66$ for cathodic arc, ${ }^{12}$ at film growth temperature $T_{s} \sim 500{ }^{\circ} \mathrm{C}$. We show that the simultaneous control of metal ion flux $J_{M e+}$, metal ion energy $E_{i}$, and metal ion charge (1+vs. 2+) plays a determinant role in optimizing ion-irradiation-induced near-surface mixing while suppressing the chemical driving force for phase decomposition ${ }^{13}$ and allowing the synthesis of high-AlN-content metastable $\mathrm{Ti}_{1-x} \mathrm{Al}_{x} \mathrm{~N}$ films exhibiting both high hardness and low residual stress.

All $\mathrm{Ti}_{1-\mathrm{x}} \mathrm{Al}_{\mathrm{x}} \mathrm{N}$ films were grown in a $\mathrm{CC} 800 / 9$ CemeCon $\mathrm{AG}$ magnetron sputtering system. ${ }^{14}$ The Ti and Al targets are cast rectangular plates with dimensions $88 \times 500 \mathrm{~mm}^{2} . \mathrm{Si}(001)$ substrates, $30 \times 10 \mathrm{~mm}^{2}$, are mounted symmetrically with respect to the targets, which are tilted toward the substrate, resulting in a $21^{\circ}$ angle between the substrate normal and a line connecting the center of the target with the center of the substrate. The target-to-substrate distance is 180 $\mathrm{mm}$. Substrates are cleaned sequentially in acetone and isopropanol alcohol and mounted with clips such that their long sides are parallel to the long sides of the targets. The system base pressure is $<0.3 \mathrm{mPa}\left(2.3 \times 10^{-6}\right.$ Torr) and the total pressure $P_{\text {tot }}$ during deposition is $0.4 \mathrm{~Pa}$ (3 mTorr) with a $\mathrm{N}_{2} / \mathrm{Ar}$ flow ratio of 0.2 . The film growth temperature $T_{s}$ is $500{ }^{\circ} \mathrm{C}$.

A hybrid powering scheme is used in which one of the magnetron targets is operated in HIPIMS mode, while the other is operated as a conventional dc magnetron. The AlN concentration in as-deposited $\mathrm{Ti}_{1-x} \mathrm{Al}_{x} \mathrm{~N}$ films is controlled by varying the average power to the dc 
magnetron, while maintaining the HIPIMS power constant. Two series of films are deposited. In the first set, the Al target is powered with HIPIMS, while the Ti target is operated with DCMS (Al-HIPIMS/Ti-DCMS). The positions of the targets are then switched for the Ti-HIPIMS/AlDCMS growth experiments.

The average power to the Al HIPIMS target during Al-HIPIMS/Ti-DCMS operation is set at $2.5 \mathrm{~kW}(5 \mathrm{~J} /$ pulse, $500 \mathrm{~Hz}, 10 \%$ duty cycle, limited by arcing in reactive mode), while the DCMS power (Ti target) is varied between 1.4 and $2.5 \mathrm{~kW}$ resulting in an AlN film concentration ranging from $x=0.56$ to 0.76 . For Ti-HIPIMS/Al-DCMS, an average HIPIMS power of $5 \mathrm{~kW}$ (10 J/pulse, $500 \mathrm{~Hz}, 10 \%$ duty cycle) is required to obtain films with comparable compositions since the Ti sputtering rate is approximately half that of Al. The DCMS power on the Al target is varied from $1 \mathrm{~kW}$ (resulting in $x=0.53)$ to $2 \mathrm{~kW}(x=0.74)$.

A pulsed substrate bias, $V_{s}=-60 \mathrm{~V}$, synchronized with the HIPIMS pulse, is used in all experiments. Between HIPIMS pulses, the substrate is at floating potential, -10 V. AlN and TiN coverages deposited per HIPIMS pulse are $4.2 \times 10^{-3} \AA$ and $1.6 \times 10^{-3} \AA$, respectively. Coverages deposited from dc sources between HIPIMS pulses are thus limited to $<6.3 \times 10^{-3} \AA$ for $\mathrm{Al}$ HIPIMS/Ti-DCMS and $<4.5 \times 10^{-3} \AA$ for Ti-HIPIMS/Al-DCMS in order to maintain film compositions within the desired concentration range. Total layer thicknesses are $810 \mathrm{~nm}$ to 2.9 $\mu \mathrm{m}$.

As-deposited $\mathrm{Ti}_{1-x} \mathrm{Al}_{x} \mathrm{~N}$ alloy film compositions are determined by time-of-flight elastic recoil detection analysis (ToF-ERDA). X-ray diffraction (XRD) and cross-sectional transmission electron microscopy (XTEM) are used to characterize film microstructure, while nanoindentation hardness $H$ and residual film stress $\sigma$ are obtained from Berkovich nanoindentation measurements and XRD $\sin ^{2} \psi$ analyses, ${ }^{15}$ respectively. The composition and energy of ions 
incident at the growing film as a function of target power and configuration are obtained from insitu mass spectroscopy measurements in which the acceptance orifice of the spectrometer is parallel to, and $180 \mathrm{~mm}$ (the target-substrate distance during film growth) from, each target surface.

As-deposited layers are post-annealed in an Ar atmosphere in order to evaluate the thermal stability and temperature-dependent properties of $\operatorname{Ti}_{1-x} \mathrm{Al}_{x} \mathrm{~N}$ alloys as a function of $\mathrm{AlN}$ concentration. Films are annealed for $2 \mathrm{~h}$ at temperatures $T_{a}$ ranging from 800 to $1200{ }^{\circ} \mathrm{C}$. The heating rate is maintained at $7{ }^{\circ} \mathrm{C} / \mathrm{min}$ between room temperature and $\left(T_{a}-40\right){ }^{\circ} \mathrm{C}$, then reduced to $5{ }^{\circ} \mathrm{C} / \mathrm{min}$. Sample cooling rates depend on $T_{a}$ and vary from $3.3{ }^{\circ} \mathrm{C} / \mathrm{min}$ at $T_{a}=800{ }^{\circ} \mathrm{C}$ to 7.8 ${ }^{\circ} \mathrm{C} / \mathrm{min}$ at $T_{a}=1200{ }^{\circ} \mathrm{C}$ as the temperature is decreased from $T_{a}$ to $500{ }^{\circ} \mathrm{C}$, after which the cooling rate is decreased to $1.6^{\circ} \mathrm{C} / \mathrm{min}$.

The choice of target configuration is found to have a dramatic effect on the microstructure and physical properties of $\mathrm{Ti}_{1-x} \mathrm{Al}_{x} \mathrm{~N}$ alloy films with similar AlN concentrations ranging from $x \sim$ 0.50 to 0.65 . Alloy films grown using the Al-HIPIMS/Ti-DCMS configuration exhibit high hardness ( 30 GPa) with low stress levels $(0.2-0.7 \mathrm{GPa}$, tensile). This is a unique combination of properties for $\mathrm{Ti}_{1-x} \mathrm{Al}_{x} \mathrm{~N}$ films in which high $H$ values are generally the result of high compressive stress. ${ }^{16}$ For example, $H$ values of $31.5 \mathrm{GPa}$ are reported for $\mathrm{Ti}_{0.34} \mathrm{Al}_{0.66} \mathrm{~N}$ layers grown at $T_{s}=400{ }^{\circ} \mathrm{C}$ by cathodic arc evaporation, ${ }^{17}$ but applications of such films are limited by intrinsic compressive stresses ranging from -3.1 (ref. 12) to $-9.1 \mathrm{GPa}^{18} \mathrm{In}$ contrast to AlHIPIMS/Ti-DCMS alloy samples, films grown in the Ti-HIPIMS/Al-DCMS configuration, exhibit low hardness, 18-19 GPa, and relatively high residual compressive stress, 1.4 to $2.7 \mathrm{GPa}$.

The large difference in hardness between Al-HIPIMS/Ti-DCMS and Ti-HIPIMS/AlDCMS alloys is primarily due to differences in phase content. $\mathrm{Ti}_{1-x} \mathrm{Al}_{x} \mathrm{~N}$ films grown with the 
former target configuration are single-phase $\mathrm{NaCl}$-structure alloys with $x$ up to a kinetic solubility limit of $x_{\max }=0.64$, whereas Ti-HIPIMS/Al-DCMS films are two-phase with an increasing volume fraction of hexagonal AlN over the entire concentration range. This is illustrated in Fig. 1, showing typical XTEM images, with corresponding selected-area electron diffraction (SAED) patterns, of layers with similar compositions: (a) a $\mathrm{Ti}_{0.47} \mathrm{Al}_{0.53} \mathrm{~N}$ layer grown in the $\mathrm{Ti}$ HIPIMS/Al-DCMS configuration and (b) a $\mathrm{Ti}_{0.41} \mathrm{Al}_{0.59} \mathrm{~N}$ film grown by Al-HIPIMS/Ti-DCMS. The Ti-HIPIMS/Al-DCMS film has hardness $H=18.7 \mathrm{GPa}$ and tensile residual stress $\sigma=-1.4$ GPa, while $H=29.8 \mathrm{GPa}$ and $\sigma=+0.8 \mathrm{GPa}$ are obtained with Al-HIPIMS/Ti-DCMS. Both samples exhibit a dense columnar structure with no open boundaries and an average column diameter of $30 \pm 10 \mathrm{~nm}$. The SAED pattern from the $x=0.53 \mathrm{Ti}-\mathrm{HIPIMS} / \mathrm{Al}-\mathrm{DCMS}$ film consists of both cubic (111, 002, and 022) and wurtzite (0002 and 1010) diffraction rings. The SAED pattern from the $\mathrm{Ti}_{1-x} \mathrm{Al}_{x} \mathrm{~N}$ film grown under periodic $\mathrm{Al}^{+}$bombardment from the Al-HIPIMS target, despite having a higher AlN concentration (thus, a larger driving force toward decomposition), contains only $\mathrm{NaCl}$-structure diffraction rings (111, 002, and 022). Neither film has strong preferred orientation.

Additional evidence for the dependence of cubic AlN solubility in metastable $\operatorname{Ti}_{1-x} \mathrm{Al}_{x} \mathrm{~N}$ on target configuration is presented in Fig. 2, where the relaxed lattice parameter $a_{o}$, obtained at the strain-free tilt angle $\psi^{*}$ of $34.4^{\circ}$ (using the alloy Poisson ratio $v=0.19$ from Ref. 19 ), ${ }^{20}$ is plotted as a function of $x$ for films grown in both the Al-HIPIMS/Ti-DCMS and Ti-HIPIMS/Al-DCMS configurations. Consistent with the SAED patterns, XRD $\theta-2 \theta$ scans show that Al-HIPIMS/TiDCMS films with $x<0.65$ are single-phase with the $\mathrm{NaCl}$ structure and relaxed lattice parameters $a_{o}(x)$ which decrease linearly from $4.174 \AA$ with $x=0.56$ to $4.160 \AA$ with $x=0.64$, in good agreement with results of density functional theory calculations based upon projector 
augmented wave methods. ${ }^{21}$ With $x>0.65, a_{o}(x)$ remains constant at $4.160 \AA$ as elastically-soft ${ }^{22}$ second-phase wurtzite-structure AlN precipitates out of solution. Thus, alloy film hardness $H(x)$ decreases from 26.7 GPa with $x=0.64$ to 18.6 and $14.3 \mathrm{GPa}$ with $x=0.67$ and 0.72 .

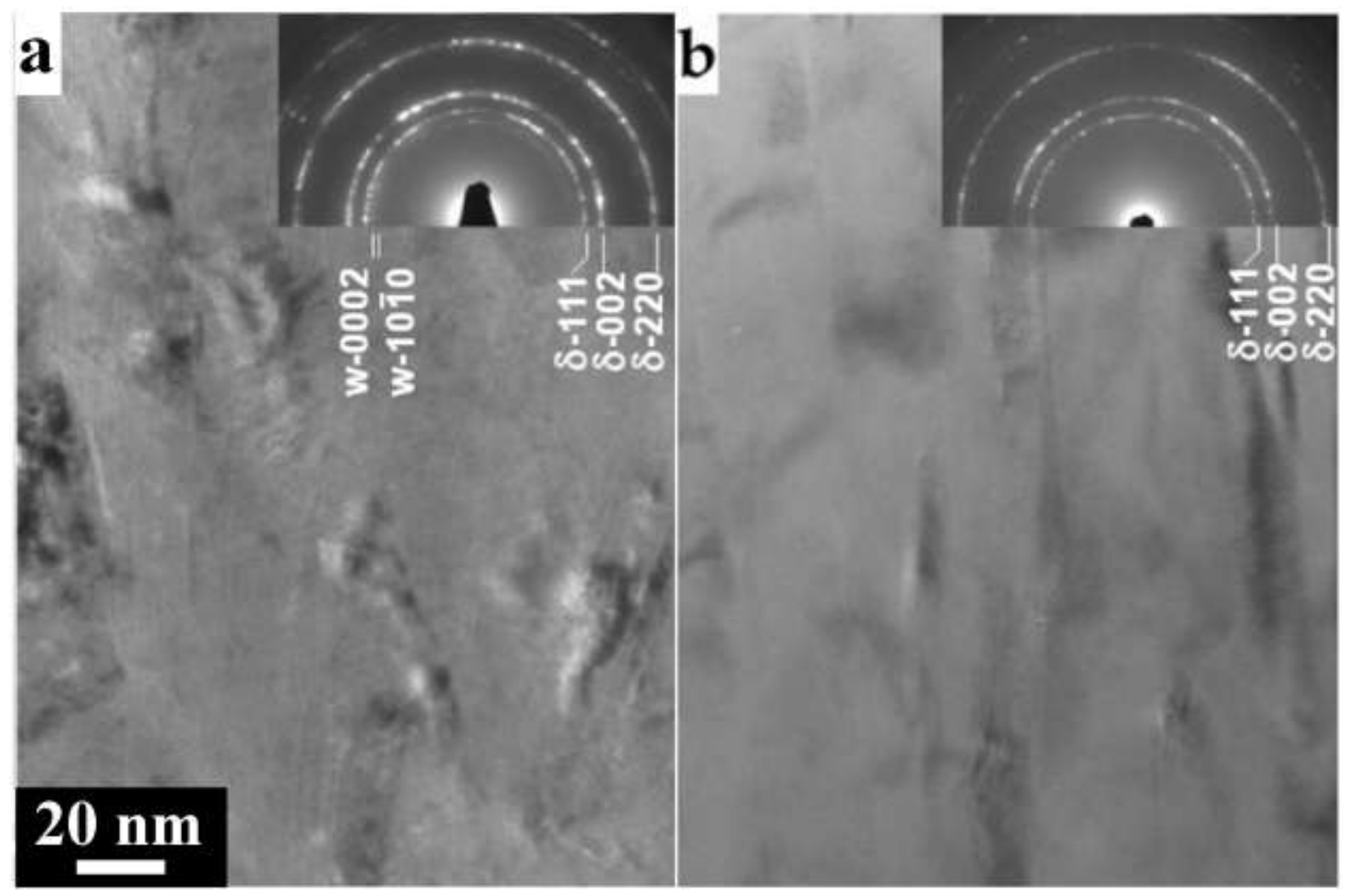

Fig. 1 XTEM images and corresponding selected area diffraction patterns (see inserts) from $\mathrm{Ti}_{1-x} \mathrm{Al}_{x} \mathrm{~N}$ alloys with composition $x$ : (a) $x=0.53$, Ti-HIPIMS/Al-DCMS and (b) $x=$ 0.59, Al-HIPIMS/Ti-DCMS.

$\theta-2 \theta$ XRD results for Ti-HIPIMS/Al-DCMS $\mathrm{Ti}_{1-x} \mathrm{Al}_{x} \mathrm{~N}$ films show, in agreement with SAED patterns, that all layers with AlN concentrations $0.53 \leq x \leq 0.66$ are two phase. $H(x)$ and $a_{o}(x)$ remain essentially constant over this composition range at $\sim 19 \mathrm{GPa}$ and $4.213 \pm 0.003 \AA$. The latter corresponds, based upon previous results for single-phase alloy layers grown by cathodic arc ion plating, ${ }^{10}$ to cubic $\mathrm{Ti}_{1-x} \mathrm{Al}_{x} \mathrm{~N}$ with $x \sim 0.40$. This suggests a kinetic AlN solubility limit $x_{\max }$ 
in the cubic TiN matrix of $\square 0.40$ for Ti-HIPIMS/Al-DCMS; higher AlN concentrations give rise to the formation of wurtzite-structure second-phase precipitates.

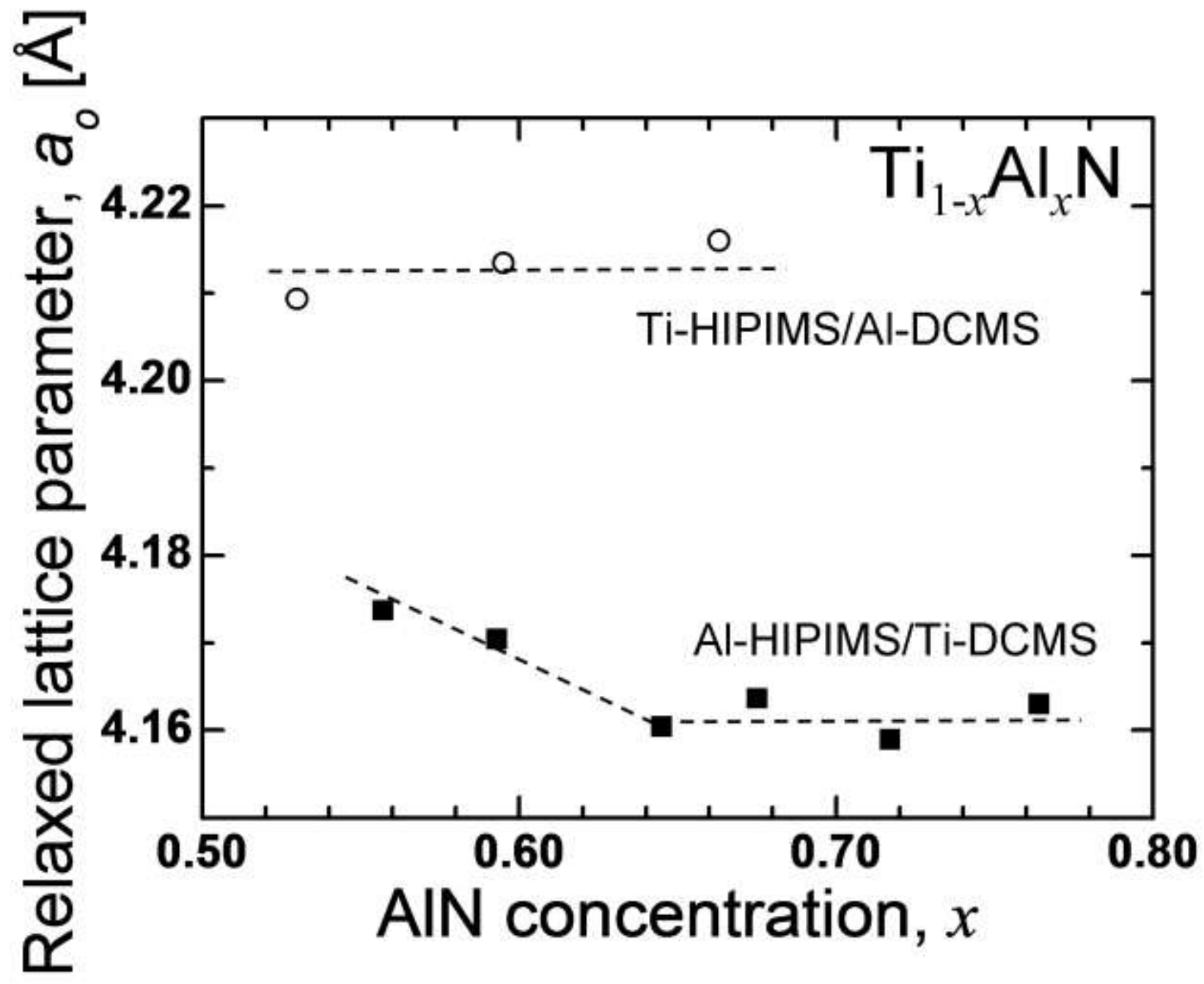

Fig. 2 Relaxed lattice parameters $a_{o}$ of $\mathrm{NaCl}$-structure $\operatorname{Ti}_{1-x} \mathrm{Al}_{x} \mathrm{~N}$ films, grown using $\mathrm{Al}$ HIPIMS/Ti-DCMS (filled squares) and Ti-HIPIMS/Al-DCMS (open circles) target configurations as a function of AIN concentration $x$.

The observed differences in phase composition and AlN solubility limits between AlHIPIMS/Ti-DCMS and Ti-HIPIMS/Al-DCMS films with comparable compositions stem from significant differences in ion irradiation during film growth. The results of in-situ ion mass spectroscopy studies carried out at the substrate position are summarized in Table 1. For both 
target configurations, the mean energies of metal and gas ions incident at the growing film surface during de magnetron sputter deposition between HIPIMS pulses are low and do not exceed $15 \mathrm{eV}$, including the floating potential.

Tab. 1 Mean ion energy (eV) and percentage contribution to the total ion flux (in parentheses) for all four target configurations. (*) indicates an upper-limit value obtained in separate experiments in which a TiAl target $(70 \mathrm{at} \% \mathrm{Al})$ is sputtered in pure $\mathrm{Ar}$ in order to avoid signal overlap between $\mathrm{Al}^{2+}$ and $\mathrm{N}^{+}$ions.

\begin{tabular}{|c|c|c|c|c|c|c|c|c|}
\hline In & $\mathrm{Al}^{+}$ & $\mathrm{Al}^{2+}$ & $\mathrm{Ti}^{+}$ & $\mathrm{Ti}^{2+}$ & $\mathrm{Ar}^{+}$ & $\mathrm{Ar}^{2+}$ & $\mathrm{N}^{+}$ & $\mathrm{N}^{+}$ \\
\hline Al-HIPIMS & $\begin{array}{c}11.4 \\
(27.4 \%)\end{array}$ & $(0.05 \%)^{*}$ & - & - & $\begin{array}{c}1.8 \\
(37.3 \%)\end{array}$ & $\begin{array}{c}10.5 \\
(1.4 \%)\end{array}$ & $\begin{array}{c}3.7 \\
(22.2 \%)\end{array}$ & $\begin{array}{c}7.7 \\
(11.7 \%)\end{array}$ \\
\hline Al-DCMS & $\begin{array}{c}3.4 \\
(5.8 \%)\end{array}$ & - & - & - & $\begin{array}{c}2.2 \\
(85.5 \%)\end{array}$ & $\begin{array}{c}6.2 \\
(0.5 \%)\end{array}$ & $\begin{array}{c}2.5 \\
(8.1 \%)\end{array}$ & $\begin{array}{c}5.5 \\
(0.1 \%)\end{array}$ \\
\hline Ti-HIPIMS & - & - & $\begin{array}{c}17.7 \\
(17.9 \%)\end{array}$ & $\begin{array}{c}20.8 \\
(7.5 \%)\end{array}$ & $\begin{array}{c}3.6 \\
(26.8 \%)\end{array}$ & $\begin{array}{c}15.9 \\
(0.8 \%)\end{array}$ & $\begin{array}{c}3.7 \\
(12.2 \%)\end{array}$ & $\begin{array}{c}15.2 \\
(34.8 \%)\end{array}$ \\
\hline Ti-DCMS & - & - & $\begin{array}{c}4.8 \\
(10 \%)\end{array}$ & $\begin{array}{c}8.9 \\
(0.2 \%)\end{array}$ & $\begin{array}{c}2.3 \\
(84 \%)\end{array}$ & $\begin{array}{c}7.2 \\
(0.8 \%)\end{array}$ & $\begin{array}{c}2.8 \\
(4.9 \%)\end{array}$ & $\begin{array}{c}11.8 \\
(0.1 \%)\end{array}$ \\
\hline
\end{tabular}

During the high-energy HIPIMS pulses, measured metal-ion-energy distribution functions (IEDFs) are broad with high-energy tails, which, in combination with the synchronously applied substrate bias $V_{s}$ during the pulse, contribute to a large increase in time-averaged $E_{i}$ values. Of crucial importance is the high flux of doubly-ionized metal ions. $\mathrm{Ti}^{2+}$ constitutes $\sim 30 \%$ of the total metal ion flux obtained in the Ti-HIPIMS/Al-DCMS configuration; however, the $\mathrm{Al}^{2+}$ flux during Al-HIPIMS/Ti-DCMS is insignificant. ${ }^{23}$ Not only is the average $\mathrm{Ti}^{2+}$ ion energy high $(20.8 \mathrm{eV})$, but the energy gain due to the applied substrate bias, $V_{s}=60 \mathrm{~V}$, is twice that for singly-ionized species. At $V_{s}=60 \mathrm{~V}$, the average energy of $\mathrm{Ti}^{2+}$ ions incident at the film is $>140$ $\mathrm{eV}$ during the HIPIMS pulse. This leads to the production of residual point defects ${ }^{1,24}$ which are manifested in XTEM images (Fig. 1a) as speckle contrast due to local strain fields associated with point defect complexes. The defects can serve as nucleation centers for the formation of wurtzite-structure AlN precipitates at relatively low AlN concentrations ( $x \square 0.40$ ). As a 
consequence of phase separation, $H$ is low and close to that of hexagonal AlN, whereas the residual stress is high (-2.7 GPa) and leads to film delamination during post-annealing.

However, metastable single-phase $\mathrm{NaCl}$-structure $\mathrm{Ti}_{1-x} \mathrm{Al}_{x} \mathrm{~N}$ alloys grown using the $\mathrm{Al}$ HIPIMS/Ti-DCMS configuration exhibit a relatively high kinetic solid-solubility limit $\left(x_{\max }=\right.$ 0.64), and the films have high hardness $(H \sim 30 \mathrm{GPa})$ with low residual tensile stress $(0.2-0.7$ GPa), all of which are difficult to achieve using DCMS alone or by cathodic arc deposition. We attribute this to a combination of kinetically-limited growth and dynamic near-surface mixing due predominantly to low-energy $\mathrm{Al}^{+}$and $\mathrm{Ar}^{+}$ion irradiation during HIPIMS pulses (the $\mathrm{Al}^{2+}$ flux is negligible). Ion mixing is facilitated by enhanced momentum transfer from the metal ions. Ion energies of $60-70 \mathrm{eV}$, with $J_{i} / J_{M e}=2-3$, are sufficiently low to avoid formation of detectable residual ion damage.

High $H$ values are typically the result of high compressive stress in which case both $H$ and $\sigma$ decrease during post-annealing as residual point defects are annealed out. ${ }^{16}$ To further demonstrate that this is not the case here, Al-HIPIMS/Ti-DCMS $\operatorname{Ti}_{1-x} \mathrm{Al}_{x} \mathrm{~N}$ samples with high hardness $(x=0.59)$, corresponding to the XTEM image in Figure $1(b)$, are annealed for $2 \mathrm{~h}$ at temperatures $T_{a}$ ranging, in steps of $100{ }^{\circ} \mathrm{C}$, from 800 to $1200{ }^{\circ} \mathrm{C}$. Film hardnesses $H$ are remeasured following annealing and the results are shown in Figure 3, where each data point corresponds to a different sample. The as-deposited hardness, $H=29.8 \mathrm{GPa}$, initially increases to 31.4 GPa at $800{ }^{\circ} \mathrm{C}$ and $33.0 \mathrm{GPa}$ at $900{ }^{\circ} \mathrm{C}$, before decreasing to $26.2,23.5$, and $23.1 \mathrm{GPa}$ at 1000,1100 , and $1200{ }^{\circ} \mathrm{C}$, respectively.

$\theta-2 \theta$ XRD measurements, carried out as a function of tilt angle $\psi$ on $\mathrm{Ti}_{0.41} \mathrm{Al}_{0.59} \mathrm{~N}$ AlHIPIMS/Ti-DCMS films annealed at $900{ }^{\circ} \mathrm{C}$ reveal that the 111 and 002 diffraction peaks from the cubic phase are highly asymmetric, especially at large tilt angles, suggesting that the cubic 
AlN phase is present predominantly in the near-surface region. An example of such results is shown in Figure 4 for $\psi^{*}=34.4^{\circ}$, together with corresponding data for the as-deposited sample. Apart from the asymmetry caused by the additional contribution from the cubic AlN phase, note that the diffraction peaks from the post-annealed sample shift toward lower diffraction angles, close to that of the TiN phase, confirming the spinodal decomposition reaction path $c-(\mathrm{Ti}, \mathrm{Al}) \mathrm{N}$ $\rightarrow c-\mathrm{TiN}+c-\mathrm{AlN}$

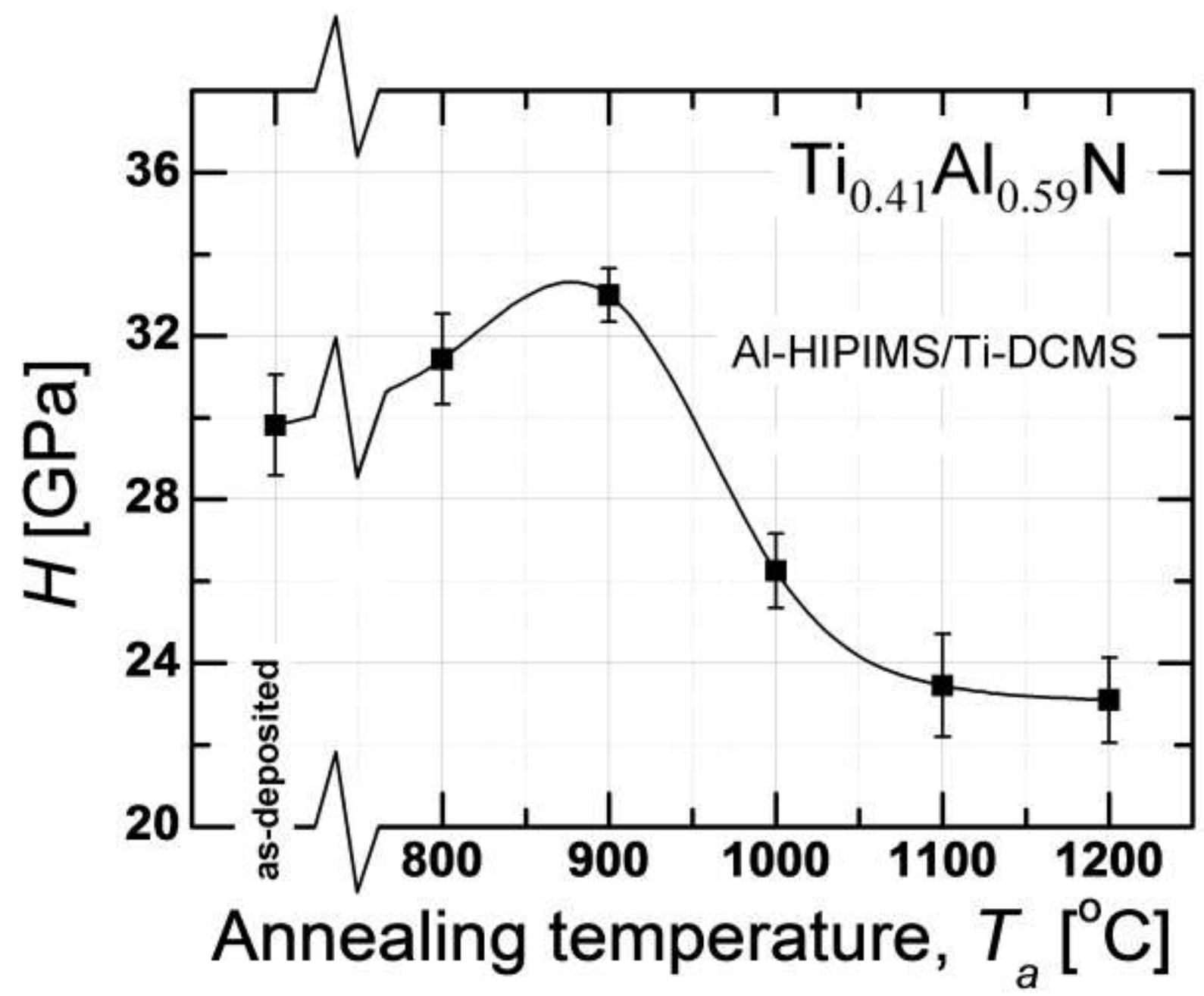

Fig. 3. Hardness $H$ plotted versus annealing temperature $T_{a}$ for $\mathrm{Ti}_{0.41} \mathrm{Al}_{0.59} \mathrm{~N}$ samples grown using the Al-HIPIMS/Ti-DCMS target configuration. 


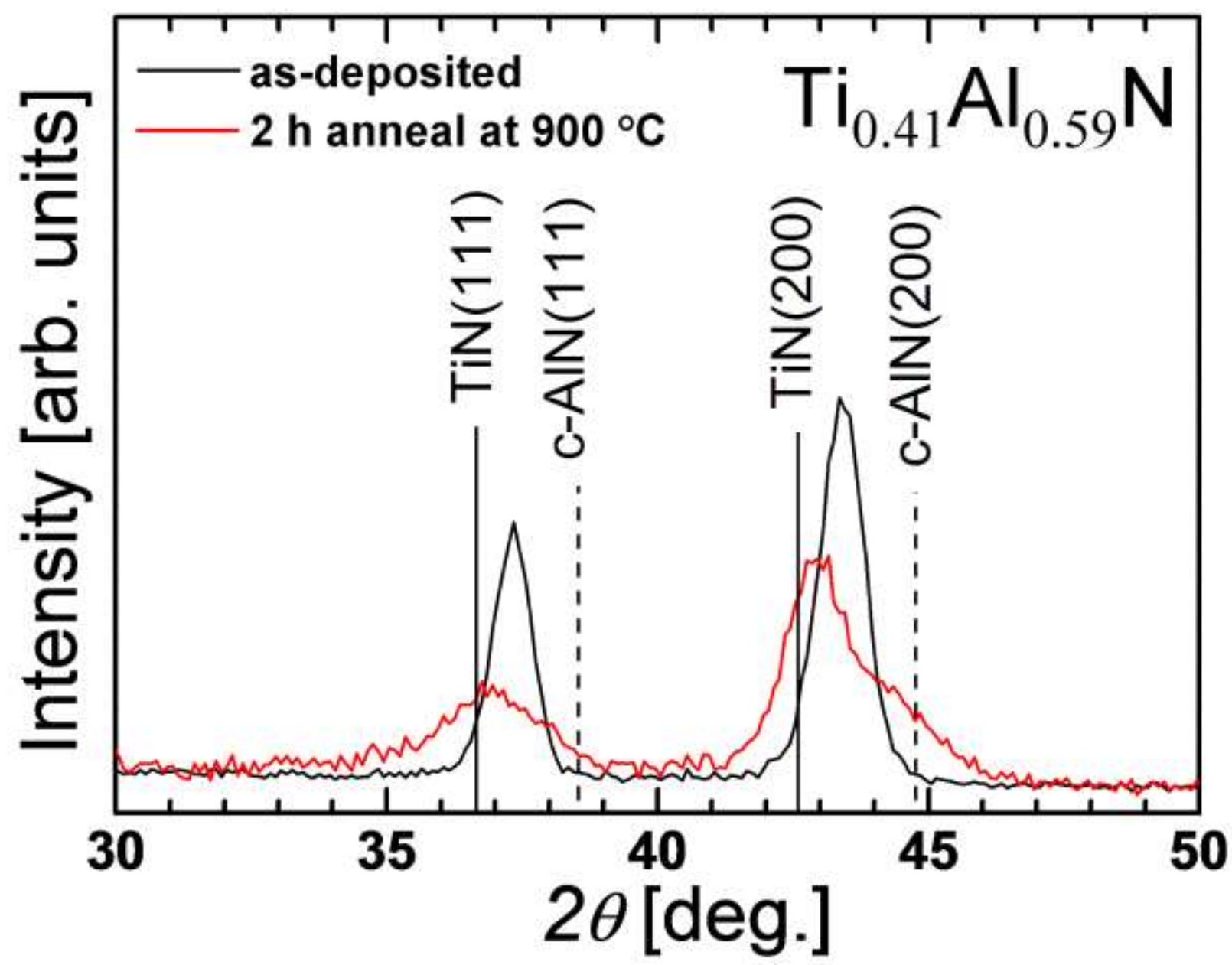

Fig. $4 \theta-2 \theta$ scans recorded at the strain-free tilt angle $\psi^{*}=34.4^{\circ}$ for Al-HIPIMS/Ti-DCMS $\mathrm{Ti}_{0.41} \mathrm{Al}_{0.59} \mathrm{~N}$ alloy films as-deposited (in black) and following a $2 \mathrm{~h}$ anneal at $900{ }^{\circ} \mathrm{C}$ (in red).

The observed increase in $H$ upon post-deposition annealing at $900{ }^{\circ} \mathrm{C}$ clearly shows that high hardness values measured for as-deposited films are not the consequence of high compressive stresses. $\mathrm{Ti}_{0.41} \mathrm{Al}_{0.59} \mathrm{~N}$ film hardness increases to $33 \mathrm{GPa}$ at $900{ }^{\circ} \mathrm{C}$ due to the formation of coherent cubic AlN via spinodal decomposition. At higher annealing temperatures ( $\geq 1000{ }^{\circ} \mathrm{C}$ ), the precipitation of second-phase wurtzite-structure AlN results in $H$ decreasing below the value of as-deposited films. For films deposited in the Ti-HIPIMS/Al-DCMS configuration, high residual compressive stress levels lead to film delamination during postannealing. 
In summary, we use a hybrid HIPIMS/DCMS co-sputtering configuration, in which one target (either Ti or $\mathrm{Al}$ ) is powered by HIPIMS while the other is powered by DCMS, to grow metastable $\mathrm{Ti}_{1-x} \mathrm{Al}_{x} \mathrm{~N}$ alloy films with compositions $0.4 \leq x \leq 0.76$. Markedly different film growth pathways are obtained depending upon which target is powered by HIPIMS. With TiHIPIMS/Al-DCMS, the layers are two-phase with low hardness and high compressive stress primarily due to the presence of an intense flux of doubly-ionized $\mathrm{Ti}^{2+}$ ions, with total kinetic energies $>140 \mathrm{eV}$, which give rise to the creation of the residual defects and hence, high compressive stress. The defects serve as nucleation centers for the formation of wurtzite-structure AlN precipitates which decrease film hardness. In sharp distinction, alloys grown in the AlHIPIMS/Ti-DCMS mode have a much higher kinetic solid-solubility limit, $x_{\max }=0.64$, high hardness, due to solid-solution hardening, and low residual tensile stress, all of which are difficult to achieve by either DCMS alone or by cathodic arc deposition. We attribute this to a combination of kinetically-limited growth and dynamic low-energy near-surface mixing due predominantly to $\mathrm{Al}^{+}$and $\mathrm{Ar}^{+}$ion irradiation during HIPIMS pulses. Finally, cubic $\mathrm{Ti}_{0.41} \mathrm{Al}_{0.59} \mathrm{~N}$ alloy films exhibit age hardening giving rise to a $10 \%$ increase in $H$ during annealing at $900{ }^{\circ} \mathrm{C}$.

The financial support from the European Research Council (ERC) through an Advanced Grant is acknowledged. We thank the staff at CemeCon AG and at the Tandem Laboratory, Uppsala University, for technical support. 


\section{References}

${ }^{1}$ I. Petrov, P.B. Barna, L. Hultman, J.E. Greene, Microstructural evolution during film growth J. Vac. Sci. Technol. A 21 (2003) 117

${ }^{2}$ F. Adibi, I. Petrov, J.E. Greene, L. Hultman, J.-E. Sundgren, Effects of high-flux low-energy (20-100 eV) ion irradiation during deposition on the microstructure and preferred orientation of $T_{0.5} A l_{0.5} \mathrm{~N}$ alloys grown by ultra-high-vacuum reactive magnetron sputtering J. Appl. Phys. 73 (1993) 8580

${ }^{3}$ V. Kouznetsov, K. Macak, J.M. Schneider, U. Helmersson and I. Petrov, A novel pulsed magnetron sputter technique utilizing very high target power densities Surf. Coat. Tech. 122 (1999) 290

${ }^{4}$ J. Böhlmark, J. Alami, C. Christou, A.P. Ehiasarian, U. Helmersson, Ionization of sputtered metals in high power pulsed magnetron sputtering J. Vac. Sci. Technol. A 23 (2005) 18

${ }^{5}$ S.M. Rossnagel, Gas density reduction effects in magnetrons J. Vac. Sci. Technol. A 6 (1988) 19

${ }^{6}$ S.M. Rossnagel, H.R. Kaufman, Current-voltage relations in magnetrons J. Vac. Sci. Technol. A $6(1988) 223$

${ }^{7}$ I. Petrov, L. Hultman, J.-E. Sundgren, J.E. Greene, Polycrystalline TiN films deposited by reactive bias magnetron sputtering: Effects of ion bombardment on resputtering rates, film composition, and microstructure J. Vac. Sci. Technol. A 10 (1992) 265

${ }^{8}$ G. Greczynski and L. Hultman, Time and energy resolved ion mass spectroscopy studies of the ion flux during high power pulsed magnetron sputtering of $\mathrm{Cr}$ in $\mathrm{Ar}$ and $\mathrm{Ar} / \mathrm{N}_{2}$ atmospheres Vacuum 84 (2010) 1159-1170 
${ }^{9}$ J. Andersson, A. P. Ehiasarian, A. Anders, Observation of $\mathrm{Ti}^{4+}$ ions in a high power impulse magnetron sputtering plasma Applied Physics Letters 93 (2008) 071504

${ }^{10}$ U. Wahlström, L. Hultman, J.-E. Sundgren, F. Adibi, I. Petrov and J.E. Greene, Crystal growth and microstructure of polycrystalline $T i_{1-x} A l_{x} N$ alloy films deposited by ultra-high-vacuum dualtarget magnetron sputtering Thin Solid Films 235 (1993) 62-70

${ }^{11}$ F. Adibi, I. Petrov, J.E. Greene, U. Wahlstrom, J.-E. Sundgren, Design and characterization of a compact two-target ultrahigh vacuum magnetron sputter deposition system: application to the growth of epitaxial $T i_{1-x} A l_{x} N$ alloys and $T i N / T i_{1-x} A l_{x} N$ superlattices J. Vac. Sci. Technol. A 11 (1993) 136

${ }^{12}$ T. Ikeda, H. Satoh, Phase formation and characterization of hard coatings in the Ti-Al-N system prepared by the cathodic arc ion plating method Thin Solid Films 195 (1991) 99

${ }^{13}$ F. Adibi, I. Petrov, L. Hultman, U. Wahlström, T. Shimizu, D. McIntyre, J.E. Greene, Defect structure and phase transitions in epitaxial metastable cubic $\mathrm{Ti}_{0.5} A l_{0.5} \mathrm{~N}$ alloys grown on MgO(001) by ultra-high-vacuum magnetron sputter deposition J. Appl. Phys. 69 (1991) 6437

${ }^{14}$ http://www.cemecon.de/coating_technology/2_coating_units/25_cc_800sup_sup_9_hipims/ind ex_eng.html, accessed in September 2011

15 see, e.g., chapter 6 in M. Birkholz Thin Film Analysis by X-ray Scattering, Wiley-VCH, Weinheim 2006

16 P.H Mayrhofer, H. Clemens, C. Mitterer, Interfaces in nanostructured thin films and their influence on hardness Z. Metallk. 96 (2005) 468-80

17 A. Knutsson, M. P. Johansson, L. Karlsson, and M. Odén, Thermally enhanced mechanical properties of arc evaporated $T_{0.34} A l_{0.66} N / T i N$ multilayer coatings J. Appl. Phys. 108 (2010) 044312 
${ }^{18}$ C.V. Falub, A. Karimi, M. Ante, W. Kalss, Interdependence between stress and texture in arc evaporated Ti-Al-N thin films Surf. Coat. Tech. 201 (2007) 5891

${ }^{19} \mathrm{~V}$. Podgursky, Ab initio calculations of elastic properties of isotropic and oriented $\mathrm{Ti}_{1-x} A l_{x} N$ hard coatings J. Phys. D: Appl. Phys. 40 (2007) 4021-4026

${ }^{20}$ For common transition-metal nitrides, $v$ varies only from 0.17 for cubic AlN (see A.J. Wang et al. Computational Materials Science 48 (2010) 705-709) to 0.25 for TiN (cf. J.O. Kim et al. J. Appl. Phys. 72 (1992) 1805). Variation in $v$ over this range changes $\psi^{*}$ by less than $\pm 3^{\circ}$.

${ }^{21}$ B. Alling, A. Karimi, I.A. Abrikosov, Electronic origin of the isostructural decomposition in cubic $M_{1-x} A l_{x} N(M=T i, C r, S c, H f):$ A first-principles study Surf. Coat. Tech. 203 (2008) 883

${ }^{22}$ I. Yonenaga, T. Shima, H.F.S Marcel, Nanoindentation hardness and elastic moduli of bulk single-crystal AlN Jap. J. Appl. Phys. 41 (2002) 4620-1

${ }^{23}$ Since it is not possible to resolve the $\mathrm{Al}^{2+}$ from the $\mathrm{N}^{+}$signal during reactive Al-HIPIMS due to peak overlap $(\mathrm{m} / \mathrm{e}=13.5$ and 14 , respectively), the upper bounds for the relative ratios between doubly-ionized and singly-ionized $\mathrm{Al}$ ion fluxes $J_{A l^{2+} / J_{l} l^{+}}$as well as, doubly-ionized $\mathrm{Al}^{2+}$ and $\mathrm{Ti}^{2+}$ ion fluxes $J_{A l^{2+} / J_{T i}^{2+}}$ are estimated based upon an independent experiment in which a TiAl target (70 at\% $\mathrm{Al})$ is sputtered in pure Ar at $0.4 \mathrm{~Pa}$ (3 mTorr) in HIPIMS mode. The results show that the $\mathrm{Al}^{2+}$ flux $J_{A l^{2+}}$ is negligible.

${ }^{24}$ I. Petrov, L. Hultman, U. Helmersson, J. E. Sundgren, J.E. Greene, Microstructure Modification of TiN by Ion Bombardment during Reactive Sputter Deposition, Thin Solid Films, $169299(1989)$ 